Check for updates

Cite this: RSC Adv., 2019, 9, 38148

Received 5th October 2019

Accepted 16th November 2019

DOI: $10.1039 / \mathrm{c} 9 \mathrm{ra} 08074 \mathrm{k}$

rsc.li/rsc-advances

\section{An efficient multicomponent synthesis of 2,4,5- trisubstituted and 1,2,4,5-tetrasubstituted imidazoles catalyzed by a magnetic nanoparticle supported Lewis acidic deep eutectic solvent $\dagger$}

\author{
Thanh Thi Nguyen, Ngoc-Phuong Thi Le, The Thai Nguyen \\ and Phuong Hoang Tran (D)*
}

A mild and highly efficient reaction for the synthesis of 2,4,5-trisubstituted and 1,2,4,5-tetrasubstituted imidazoles catalyzed by a magnetically supported Lewis acidic deep eutectic solvent on magnetic nanoparticles (LADES@MNP) has been developed via one-pot multicomponent processes under solventfree sonication. These reactions have good to excellent yields, mild conditions, and work-up simplicity. This method represents a new method for the preparation of 2,4,5-trisubstituted and 1,2,4,5tetrasubstituted imidazoles. More importantly, LADES@MNP can be easily recovered by magnetic separation and reused five times without significant loss of catalytic activity.

\section{Introduction}

In past decade, deep eutectic solvents (DESs) have attracted much attention in both reaction media and catalysts due to their unique properties such as wide liquid range, biodegradability, excellent thermal stability, and negligible vapor pressure. ${ }^{1,2}$ Among them, Lewis acidic deep eutectic solvents (LADESs) have been intensively studied as efficient media for organic syntheses. ${ }^{3,4}$ The stable and efficient LADESs can afford the desired products in high yield and selectivity against the conventional metal halide catalysts. ${ }^{5-11}$ However, some drawbacks such as the use of a large amount of LADESs, difficulty in catalyst recovery and product separation, which can cause environmental pollution and a high-cost to the procedure, limit their application in industrial processes. The development of heterogeneous DES catalysts in organic reactions has become a significant area of research due to the advantages of these materials over traditional homogeneous DESs such as easy product separation, efficient recovery and reusability, and workup simplicity. ${ }^{12}$ However, the disadvantage of heterogeneous catalysts is their lower catalytic activity and selectivity due to the poor dispersion of heterogeneous catalysts. ${ }^{13}$ Moreover, the tedious filtration and inevitable loss of heterogeneous catalysts in the recovery can cause the high-cost issue when applied to the industrial processes. ${ }^{14}$ Recently, magnetic nanoparticle supported Lewis acidic ionic liquid catalysts have been

Department of Organic Chemistry, Faculty of Chemistry, University of Science, Vietnam National University, Ho Chi Minh City 721337, Vietnam. E-mail: thphuong@hcmus.edu.vn; Tel: +84903706762

$\dagger$ Electronic supplementary information (ESI) available. See DOI: 10.1039/c9ra08074k receiving much attention due to the advantages of their high surface areas, good stability, catalyst loading capacity, easy synthesis and functionalization, good dispersion, facile separation by an external permanent magnet. ${ }^{15-17}$ More recently, owing to the unique properties, magnetic nanoparticle supported DES as a highly efficient and easily recoverable heterogeneous catalyst in organic synthesis. ${ }^{18-20}$

Imidazoles are important bioactive heterocyclic compounds which have been proved to possess antitumor, antibacterial, fungicides, herbicides, plant growth regulators, antiviral activities. $^{21-24}$ Various protocols for preparation of imidazoles via multicomponent reaction have been tested in literature, which employs a three-component reaction of 1,2-diketone or ketomonoxime, aldehyde, and ammonium acetate, or four-component reaction of 1,2-diketone, aldehyde, primary amines, and ammonium acetate. ${ }^{25-28}$ Many of the synthetic approaches for the preparation of imidazoles suffer from one or more drawbacks such as drastic reaction conditions, low yields, by-products, prolonged reaction time, volatile organic solvent, tedious work-up processes, expensive and unrecyclable catalysts. ${ }^{29-32}$ Thus, the development of efficient and environmentally benign catalysts is still highly desirable. Herein, we disclose a one-pot multicomponent synthesis of imidazole catalyzed by magnetic nanoparticle supported Lewis acidic deep eutectic solvent (LADES@MNP) under solvent-free sonication. Interestingly, no additives and no toxic reagents were included in the current method.

\section{Results and discussion}

Firstly, magnetic nanoparticle supported Lewis acidic ionic liquid was synthesized following the previous procedure, which 
removed the coating process with TEOS. The procedure was shown in Scheme 1. Magnetite nanoparticles $\left(\mathrm{Fe}_{3} \mathrm{O}_{4}\right)$ were easily prepared through a co-precipitation method. Subsequently, these nanoparticles were coated using TEOS, functionalized using (3-chloropropyl)triethoxy-silane in toluene under sonication, and further reacted with the $[\mathrm{Urea}]_{4}\left[\mathrm{ZnCl}_{2}\right]$ to yield the magnetically retrievable Lewis acidic deep eutectic solvent LADES@MNP.

Fig. 1 illustrates the FT-IR spectra of LADES@MNP. The peak at around 580, 1095, 1645, and $3419 \mathrm{~cm}^{-1}$ were attributed to the absorption of $\mathrm{Fe}-\mathrm{O}-\mathrm{Fe}, \mathrm{Si}-\mathrm{O}-\mathrm{Si}$, and $\mathrm{O}-\mathrm{H}$ vibrations, respectively (Fig. 1b). The absorption peak at $2935 \mathrm{~cm}^{-1}$ was associated with stretching vibration of $\mathrm{C}-\mathrm{H}$ groups in $\left(\mathrm{CH}_{2}\right)_{3} \mathrm{Cl} @ \mathrm{SiO}_{2} @ \mathrm{Fe}_{3} \mathrm{O}_{4}$ (Fig. 1c). The peak around 1613, 1465, 1243,3330 , and $3449 \mathrm{~cm}^{-1}$ were caused by vibration of $\mathrm{C}=\mathrm{O}, \mathrm{C}-$ $\mathrm{N}, \mathrm{N}-\mathrm{H}$ bond in amide groups, which confirms successful immobilization. The characteristic peaks of LADES@MNP were at the same wavenumbers with the precursors, with a small shift due to the interaction between DES and the support. Besides, the Raman peak at $485 \mathrm{~cm}^{-1}$ was assigned to the $\mathrm{Zn}-\mathrm{Cl}$ stretching vibrations (Fig. S1, ESI $\dagger$ ). These results showed that magnetite nanoparticles were successfully coated with the $\mathrm{SiO}_{2}$ and then the $[\mathrm{Urea}]_{4}\left[\mathrm{ZnCl}_{2}\right]$.

Thermogravimetric analysis (TGA) of LADES@MNP displayed thermal stability up to $250{ }^{\circ} \mathrm{C}$ with a total loss of $40 \%$ mass of organic species from the nanoparticles at $250-650{ }^{\circ} \mathrm{C}$ (Fig. S2, ESI $\dagger$ ). The magnetic properties of the LADES@MNP were recorded by vibrating sample magnetometry (VSM). Fig. S3 (ESI $\dagger$ ) showed the magnetic hysteresis loops of $\mathrm{Fe}_{3} \mathrm{O}_{4}$ and LADES@MNP. The saturation magnetization value of LADES@MNP (30.8 emu g ${ }^{-1}$ ) was less than that of $\mathrm{Fe}_{3} \mathrm{O}_{4}(69.2$ emu $\mathrm{g}^{-1}$ ) due to the silica coating and the organic grafting on the surface of $\mathrm{Fe}_{3} \mathrm{O}_{4}$. However, it was sufficient for the recovery of the dispersed LADES@MNP from the reaction solution by merely using an external magnet, indicating the prepared catalyst could be separated without filtration or centrifugation.

The XRD pattern of the coated nanoparticles functionalized DES was presented in Fig. 2. The diffraction peak positions and the relative intensities of these signals in the XRD pattern of LADES@MNP are consistent with the standard $\mathrm{Fe}_{3} \mathrm{O}_{4}$ sample (COD 9006920), which confirm that the coating process does not induce any phase change of $\mathrm{Fe}_{3} \mathrm{O}_{4}$. To determine the morphologies and nanometer-sized particles of the

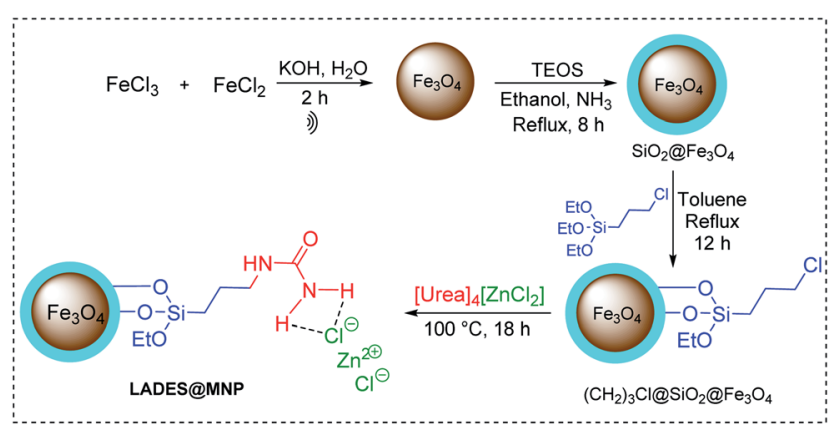

Scheme 1 The preparation of LADES@MNP catalyst.

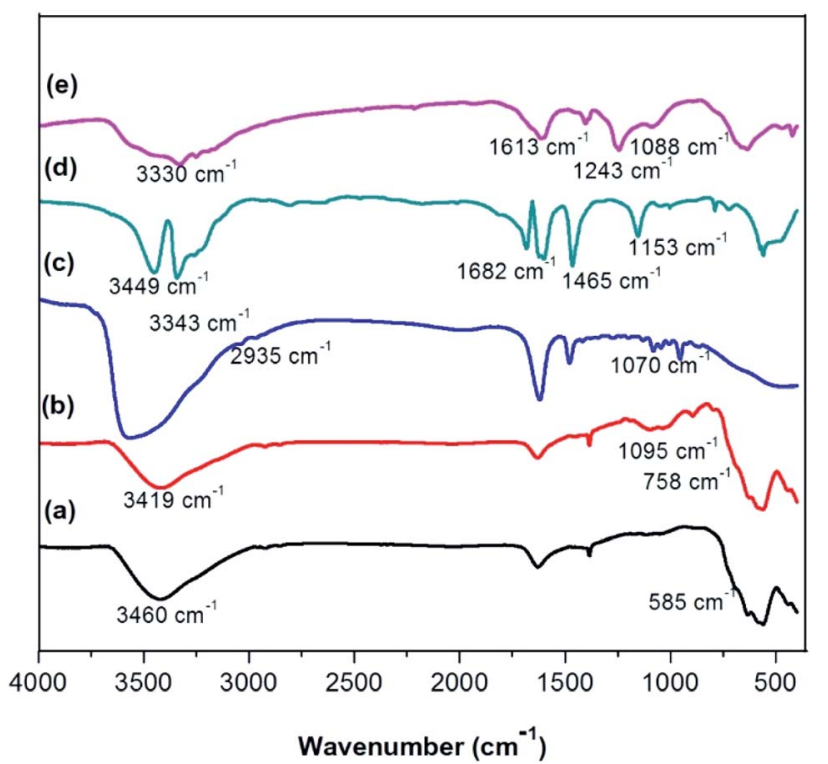

Fig. 1 FT-IR spectrum of $\mathrm{Fe}_{3} \mathrm{O}_{4}(\mathrm{a}), \mathrm{SiO}_{2}\left(\mathrm{aFe}_{3} \mathrm{O}_{4}\right.$ (b), $\left(\mathrm{CH}_{2}\right)_{3}-$ $\mathrm{Cl} @ \mathrm{SiO}_{2}\left(\mathrm{aFe}_{3} \mathrm{O}_{4}\right.$ (c), [Urea] ${ }_{4}\left[\mathrm{ZnCl}_{2}\right]$ (d), and LADES@MNP (e).

LADES@MNP catalyst, the SEM image was recorded (Fig. 3a). The image showed slight aggregation presumably due to the interaction of the layer of DES surrounding with each other and the SEM image showed the nano-sized structure of the LADES@MNP. Also, the TEM image confirmed more detailed structural information about the nano-sized structure. TEM image showed a dark $\mathrm{Fe}_{3} \mathrm{O}_{4}$ surrounded by a grey shell of silica, and the average size of the obtained particles are 15-25 $\mathrm{nm}$ (Fig. 3b).

The energy-dispersive X-ray spectroscopy (EDX) of LADES@MNP catalyst showed the presence of iron (Fe), silicon $(\mathrm{Si})$, carbon $(\mathrm{C})$, nitrogen $(\mathrm{N})$, oxygen $(\mathrm{O})$, and chlorine $(\mathrm{Cl})$ components in the structure (Fig. 3a). The EDX revealed that the mass percent of $\mathrm{Zn}$ was $26.69 \%$. Also, the content of elemental

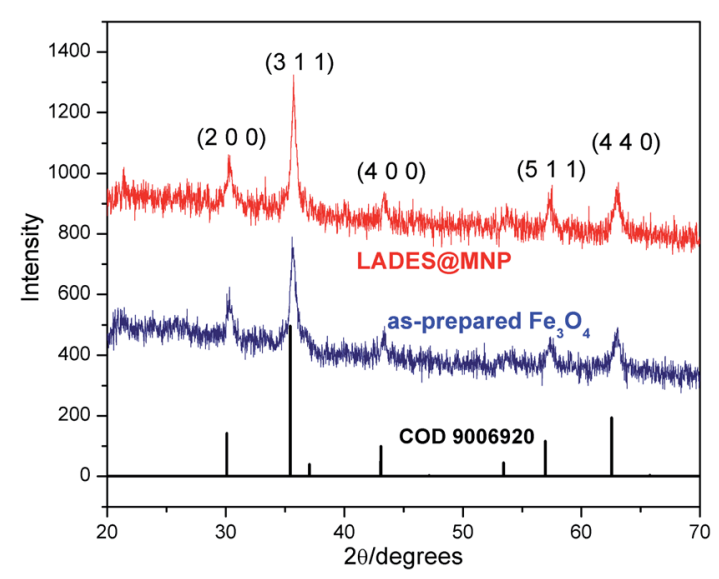

Fig. 2 X-ray diffraction pattern of LADES@MNP and $\mathrm{Fe}_{3} \mathrm{O}_{4}$. The bottom row of tick marks shows standard magnetite pattern (COD 9006920). 


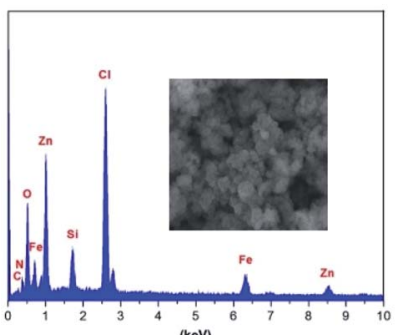

(a)

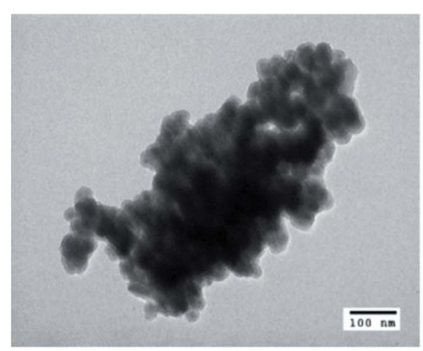

(b)
Fig. 3 SEM-EDX (a) and TEM (b) images of LADES@MNP.

$\mathrm{Zn}$ of the immobilized catalyst was found to be $277600 \mathrm{ppm}$ (corresponding to $\mathrm{Zn}^{2+}$ loading of $4.10 \mathrm{mmol} \mathrm{g}^{-1}$ ) based on inductively coupled plasma mass spectrometry (ICP-MS) analysis.

The preparation of trisubstituted imidazoles was chosen as the model reaction for the catalytic testing activity of LADES@MNP. Benzaldehyde (0.5 mmol), benzil $(0.5 \mathrm{mmol})$, and ammonium acetate $(1 \mathrm{mmol})$ were sonicated under a variety of experimental conditions. The results reported in Tables 1-3 pointing out that optimal conditions were obtained using catalytic amounts of LADES@MNP (7.5 mol\%) under solvent-free sonication for $150 \mathrm{~min}$ under solvent-free condition afforded 2,4,5-triphenyl- $1 \mathrm{H}$-imidazole as the desired product in $83 \%$ isolated yield. The use of $\mathrm{ZnCl}_{2}$, as well as other Lewis acids in optimized conditions, afforded comparably lower yields than LADES@MNP. These results were exciting and vindicated the feasibility of our approach.

Inspired by these results, in order to study the scope of this procedure, the reactions of a wide variety of aldehydes with benzil and ammonium acetate were tested under the optimal conditions (Table 4). Gratifyingly, the multicomponent reaction

Table 1 Screening catalysts for the synthesis of trisubstituted imidazoles $^{a}$
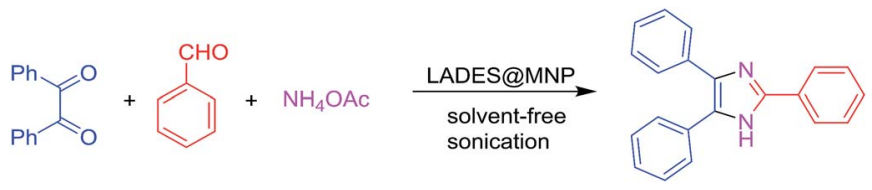

\begin{tabular}{lll}
\hline Entry & Catalyst & Isolated yield (\%) \\
\hline 1 & $\mathrm{Fe}_{3} \mathrm{O}_{4}$ & 35 \\
2 & $\mathrm{Cu}\left(\mathrm{CH}_{3} \mathrm{COO}\right)_{2}$ & 30 \\
3 & $\mathrm{CrCl}_{3}$ & 50 \\
4 & $\mathrm{ZnCl}_{2}$ & 40 \\
5 & $\mathrm{AlCl}_{3 .} \mathrm{H}_{2} \mathrm{O}$ & 60 \\
6 & $\mathrm{FeSO}_{4}$ & 60 \\
7 & $\mathrm{FeCl}_{3 \cdot 6} \mathrm{H}_{2} \mathrm{O}$ & 25 \\
8 & LADES@MNP & 83
\end{tabular}

${ }^{a}$ Condition reaction: benzil $(0.5 \mathrm{mmol})$, benzaldehyde $(0.5 \mathrm{mmol})$, ammonium acetate $(1.0 \mathrm{mmol})$, and catalyst $(7.5 \% \mathrm{mmol})$ under solvent-free sonication for $2 \mathrm{~h}$.
Table 2 Effect of solvents ${ }^{a}$

\begin{tabular}{llll}
\hline Entry & Solvent & Time $(\mathrm{min})$ & Isolated yield $(\%)$ \\
\hline 1 & Tetrahydrofuran & 120 & 20 \\
2 & 1,4-Dioxane & 120 & 50 \\
3 & Toluene & 120 & 60 \\
4 & 1,4-Dioxane & 120 & 50 \\
5 & Chloroform & 120 & 30 \\
6 & Dichloromethane & 120 & 0 \\
7 & Acetonitrile & 120 & 40 \\
8 & Dimethylsulfoxide & 120 & 55 \\
9 & Dimethylformamide & 120 & 80 \\
10 & Methanol & 120 & 55 \\
11 & Water & 120 & 15 \\
12 & Methanol : water $(1: 1)$ & 120 & 15 \\
13 & Solvent-free & 120 & 83
\end{tabular}

${ }^{a}$ Condition reaction: benzil $(0.5 \mathrm{mmol})$, benzaldehyde $(0.5 \mathrm{mmol})$, ammonium acetate $(1.0 \mathrm{mmol})$, and LADES@MNP $(7.5 \% \mathrm{mmol})$ in the presence of solvent $(1.0 \mathrm{~mL})$ under ultrasound irradiation.

catalyzed by the LADES@MNP was amenable to several substrates of aromatic aldehydes with either electron-donating or electron-withdrawing substituents under mild conditions (Table 4, entries 1-13). The present method was highly useful for the synthesis of trisubstituted imidazoles in high yields (64$93 \%$ ) with the absence of byproducts. Interestingly, heteroaromatic aldehyde such as 2-indole-carbaldehyde also afforded the corresponding imidazoles in good yield (Table 4, entry 14). Thus, the LADES@MNP acts as a highly efficient catalyst for the preparation of polysubstituted imidazoles.

To widen the scope of the current method, the preparation of tetrasubstituted imidazoles was screened through the multicomponent reactions of benzil, aromatic aldehydes, aniline, and ammonium acetate under the optimized conditions of trisubstituted imidazoles. Initially, the reaction was carried out by using stoichiometric amount of ammonium acetate $(0.5$ $\mathrm{mmol}$ ) but the desired product was obtained in low yield (62\%). If the amount of ammonium acetate was increased to $1.0 \mathrm{mmol}$, the yield was $73 \%$ and the yields were slightly improved with $1.5 \mathrm{mmol}$ and $2.0 \mathrm{mmol}$ (74\% and $76 \%$, respectively). Thus, the preparation of tetrasubstituted imidazoles was tested by using aldehydes $(0.5 \mathrm{mmol})$, benzil $(0.5 \mathrm{mmol})$, aniline $(0.5 \mathrm{mmol})$, and ammonium acetate $(1 \mathrm{mmol})$. The results were summarized

Table 3 The amount of catalyst ${ }^{a}$

\begin{tabular}{lll}
\hline Entry & LADES@MNP $(\mathrm{mol} \%)$ & Isolated yield $(\%)$ \\
\hline 1 & 0 & 20 \\
2 & 2.5 & 75 \\
3 & 5 & 60 \\
4 & 7.5 & 83 \\
5 & 10 & 83 \\
6 & 15 & 83
\end{tabular}

${ }^{a}$ Condition reactions: benzil $(0.5 \mathrm{mmol})$, benzaldehyde $(0.5 \mathrm{mmol})$ ammonium acetate $(1.0 \mathrm{mmol})$ and LADES@MNP under solvent-free sonication for $2 \mathrm{~h}$. 
Table 4 One-pot synthesis of trisubstituted imidazoles in presence of LADES@MNP as a catalyst under solvent-free sonication ${ }^{a}$

\begin{tabular}{|c|c|c|c|c|c|}
\hline Entry & $\mathrm{R}$ & Product & Time (min) & Isolated yield (\%) & Melt point $\left({ }^{\circ} \mathrm{C}\right)$ \\
\hline 1 & $\mathrm{H}$ & $1 \mathrm{a}$ & 120 & 83 & $276-277$ \\
\hline 2 & $2-\mathrm{OH}$ & $1 \mathrm{~b}$ & 120 & 93 & $212-213$ \\
\hline 3 & $3-\mathrm{OH}$ & $1 \mathrm{c}$ & 180 & 80 & $263-264$ \\
\hline 4 & $4-\mathrm{OH}$ & $1 d$ & 120 & 91 & $264-265$ \\
\hline 5 & $2-\mathrm{F}$ & $1 \mathrm{e}$ & 120 & 76 & $217-218$ \\
\hline 6 & $4-\mathrm{F}$ & $1 f$ & 120 & 64 & $253-254$ \\
\hline 7 & $4-\mathrm{NO}_{2}$ & $1 g$ & 120 & 82 & $202-203$ \\
\hline 8 & $2-\mathrm{Cl}$ & $1 \mathrm{~h}$ & 120 & 88 & $212-214$ \\
\hline 9 & $4-\mathrm{Cl}$ & $1 \mathrm{i}$ & 120 & 85 & $267-268$ \\
\hline 10 & 4-OMe & $1 \mathrm{k}$ & 120 & 84 & $258-259$ \\
\hline 11 & $4-\mathrm{N}\left(\mathrm{CH}_{3}\right)_{2}$ & 11 & 240 & 88 & $258-259$ \\
\hline 12 & $4-\mathrm{C}\left(\mathrm{CH}_{3}\right)_{3}$ & $1 \mathrm{~m}$ & 120 & 94 & $285-286$ \\
\hline 13 & $4-\mathrm{Me}$ & $1 \mathrm{n}$ & 120 & 89 & $231-232$ \\
\hline 14 & 3-Indolecarbaldehyde & 10 & 180 & 93 & $306-307$ \\
\hline
\end{tabular}

${ }^{a}$ Condition reaction: benzil $(0.5 \mathrm{mmol})$, benzaldehyde $(0.5 \mathrm{mmol})$, ammonium acetate $(1.0 \mathrm{mmol})$ and catalyst $(7.5 \% \mathrm{mmol})$ under solvent-free sonication.

in Table 5. As can be seen, electron-withdrawing substituents and electro-donating groups on the aromatic ring of aldehydes could proceed smoothly under solvent-free sonication. Regardless of the steric effects of the 2-OH, 2- $\mathrm{NO}_{2}, 2-\mathrm{COOH}$ groups, these substrates afforded the tetrasubstituted imidazoles products in high yields. Remarkably, the reactions were clean, the products were isolated easily, and no side products were detected.

The plausible mechanism is disclosed in Scheme 2. The mechanism are entirely consistent with previous literature. ${ }^{27,32,33}$ The LADES@MNP has Lewis acidic on $\mathrm{Zn}$ atoms on the surface which can participate in the bonding with the oxygen atoms on the carbonyl groups to accept nucleophiles. Moreover, we believe that a partial contribution of the nanoparticles can facilitate a high active catalysis in our method because nano-support features have a good dispersion in the reaction mixture, just like a "quasi-homogeneous" catalyst.

The turnover numbers (TONs) should be useful to evaluate the catalytic activity of solid acid. The synthesis of trisubstituted and tetrasubstituted imidazoles using benzaldehyde as substrate under optimized condition results in an attained TON of 11.1 and 9.8, respectively. Besides, the recycling of the catalyst is highly desirability for a greener process. The recovered LADES@MNP was also tested for the synthesis of trisubstituted and tetrasubstituted imidazoles (Fig. 4). LADES@MNP was easily recovered by an external magnet and washed with acetone and ethanol, dried under vacuum over $2 \mathrm{~h}$ at $80^{\circ} \mathrm{C}$, and reused in the next run. Interestingly, the catalyst was recovered in almost quantitative yield from each run. In the recyclable test, the catalytic activity of LADES@MNP could be preserved after five consecutive runs, with a slight decrease in reaction yield.
FT-IR spectra of the fresh and used LADES@MNP for five times were observed with no considerable change in functionality (Fig. 5).

Table 5 One-pot synthesis of tetrasubstituted imidazoles in the presence of LADES@MNP under solvent-free sonication ${ }^{a}$

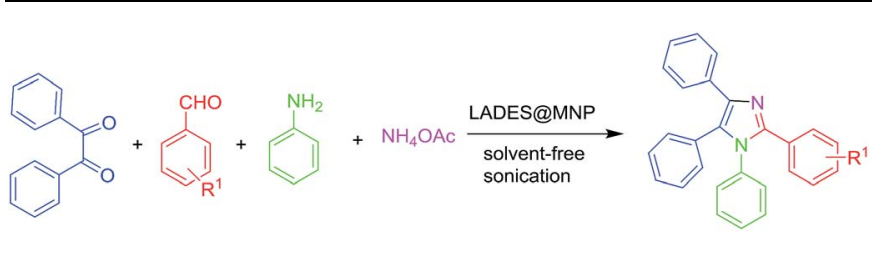

\begin{tabular}{llllll}
\multicolumn{5}{l}{ Entry $\mathrm{R}^{1}$} & \multicolumn{4}{c}{ Product Time (min) Isolated yield $(\%)$} & Melt point $\left({ }^{\circ} \mathrm{C}\right)$ \\
\hline 1 & $\mathrm{H}$ & $2 \mathrm{a}$ & 150 & $73(62)^{b}$ & $213-217$ \\
2 & $2-\mathrm{OH}$ & $2 \mathrm{~b}$ & 180 & 78 & $250-254$ \\
3 & $3-\mathrm{OH}$ & $2 \mathrm{c}$ & 120 & 80 & $202-205$ \\
4 & $4-\mathrm{OH}$ & $2 \mathrm{~d}$ & 120 & 82 & $285-289$ \\
5 & $2-\mathrm{NO}_{2}$ & $2 \mathrm{e}$ & 120 & 70 & $213-216$ \\
6 & $4-\mathrm{NO}_{2}$ & $2 \mathrm{f}$ & 120 & 90 & $194-198$ \\
7 & $4-\mathrm{F}$ & $2 \mathrm{~g}$ & 120 & 84 & $194-197$ \\
8 & $4-\mathrm{Cl}$ & $2 \mathrm{~h}$ & 180 & 74 & $184-188$ \\
9 & $4-\mathrm{OMe}$ & $2 \mathrm{k}$ & 180 & 71 & $174-177$ \\
10 & $4-\mathrm{N}\left(\mathrm{CH}_{3}\right)_{2}$ & $2 \mathrm{l}$ & 120 & 90 & $207-209$ \\
11 & $2-\mathrm{COOH}$ & $2 \mathrm{~m}$ & 120 & 93 & $294-298$ \\
12 & $4-\mathrm{C}\left(\mathrm{CH}_{3}\right)_{3}$ & $2 \mathrm{o}$ & 240 & 88 & $194-197$ \\
13 & $4-\mathrm{Me}$ & $2 \mathrm{p}$ & 120 & 75 & $187-190$ \\
14 & $2-\mathrm{OH}-5-$ & $2 \mathrm{q}$ & 120 & 93 & $200-202$
\end{tabular}

${ }^{a}$ Condition reaction: benzil $(0.5 \mathrm{mmol})$, benzaldehyde $(0.5 \mathrm{mmol})$, aniline $(0.5 \mathrm{mmol})$, ammonium acetate $(1.0 \mathrm{mmol})$ and catalyst $(7.5 \%$ $\mathrm{mmol})$ under solvent-free sonication. ${ }^{b}$ Ammonium acetate $(0.5 \mathrm{mmol})$ was used. 


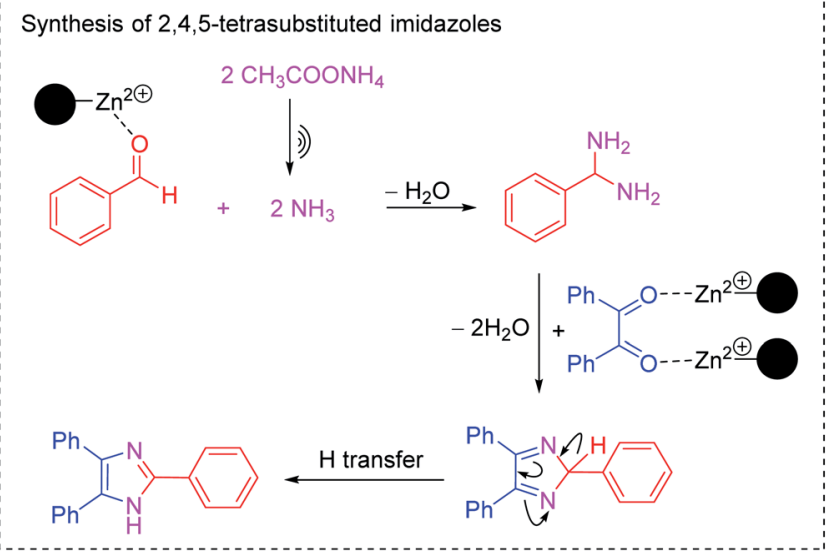

Synthesis of 1,2,4,5-tetrasubstituted imidazoles
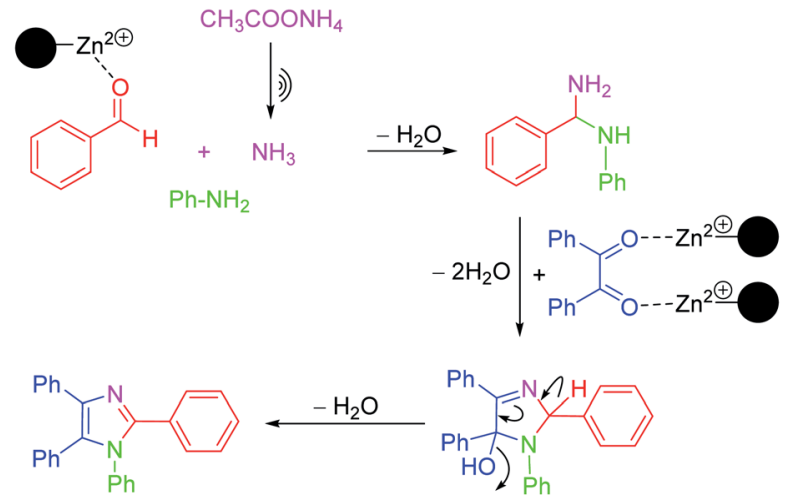

Scheme 2 Proposed mechanism for the synthesis of trisubstituted and tetrasubstituted imidazoles in the presence of LADES@MNP.

There is a capability that the active species could migrate from the LADES@MNP to the liquid phase, and the leaching acted as a homogeneous catalyst. To explore the catalyst leaching, the reaction of benzaldehyde, benzil, aniline, and ammonium acetate catalyzed by LADES@MNP was examined under optimized conditions. When the reaction time reached $60 \mathrm{~min}$, acetone $(10 \mathrm{~mL})$ was added, and the LADES@MNP was easily separated by an external magnet. The reaction mixture was divided into two parts. The desired product of part 1 was obtained in a $50 \%$ yield. Part 2 was removed the acetone and heated under the above conditions for another $90 \mathrm{~min}$ to give the product in $53 \%$ yield (less than $73 \%$ yield in general procedure). Consequently, the leaching test exhibited no contribution from homogeneous leached species of the catalyst.

\section{Experimental}

\section{Synthesis of LADES@MNP catalyst}

The catalyst was prepared via a five-step procedure in Scheme 1 . The mixture of $\mathrm{FeCl}_{2}$ and $\mathrm{FeCl}_{3}$ was dissolved in $200 \mathrm{~mL}$ water under ultrasonic irradiation. The potassium hydroxide solution $(1.0 \mathrm{M})$ was added slowly until $\mathrm{pH} 12.0$. After 120 minutes, $\mathrm{Fe}_{3} \mathrm{O}_{4}$ was washed by water and ethanol to $\mathrm{pH} 7.5$, separated by a magnet, and dried at $80{ }^{\circ} \mathrm{C}$ for $12 \mathrm{~h}$. Next, $\mathrm{Fe}_{3} \mathrm{O}_{4}$ was coated

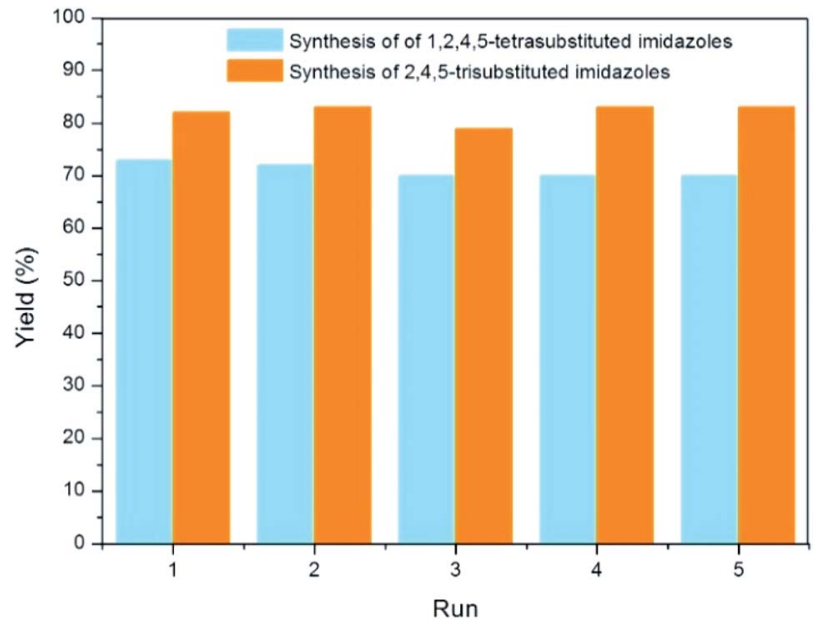

Fig. 4 Catalyst recycling studies.

with silica by refluxing mixture $\mathrm{Fe}_{3} \mathrm{O}_{4}, 3.0 \mathrm{~mL}$ ammonia solution and, $3.0 \mathrm{~mL}$ of tetraethylorthosilicate (TEOS) in $100 \mathrm{~mL}$ ethanol for $8 \mathrm{~h}$. Then, $\mathrm{Fe}_{3} \mathrm{O}_{4} @ \mathrm{SiO}_{2}$ and (3-chloropropyl)triethoxysilane $(20.0 \mathrm{mmol}, 4.820 \mathrm{~g})$ in $100 \mathrm{~mL}$ toluene were refluxed for $12 \mathrm{~h}$. The prepared $\mathrm{Fe}_{3} \mathrm{O}_{4} @ \mathrm{SiO}_{2} @\left(\mathrm{CH}_{2}\right)_{3} \mathrm{Cl}$ was separated, washed with ethanol and dried at $80{ }^{\circ} \mathrm{C}$ for $6 \mathrm{~h}$. Besides, a mixture of urea $(20.0 \mathrm{mmol}, 1.200 \mathrm{~g})$ and zinc chloride $(5.0 \mathrm{mmol}, 0.680 \mathrm{~g})$ was stirred at $100{ }^{\circ} \mathrm{C}$ until a clear colorless liquid [Urea $]_{4}\left[\mathrm{ZnCl}_{2}\right]$ was obtained. Finally, $\mathrm{Fe}_{3} \mathrm{O}_{4} @$ $\mathrm{SiO}_{2} @\left(\mathrm{CH}_{2}\right)_{3} \mathrm{Cl}(3.000 \mathrm{~g})$ and [ $\left.\mathrm{Urea}\right]_{4}\left[\mathrm{ZnCl}_{2}\right](20 \mathrm{mmol}, 1.880 \mathrm{~g})$ were added round-bottomed flask and stirred vigorously at $100{ }^{\circ} \mathrm{C}$ for $18 \mathrm{~h}$. After completion of the reaction, the LADES@MNP was collected by an external magnet, washed with ethanol $(3 \times 20 \mathrm{~mL})$ and dried under vacuum at $60{ }^{\circ} \mathrm{C}$ for $6 \mathrm{~h}$.

\section{Synthesis of polysubstituted imidazoles}

Benzil (0.5 mmol, $105 \mathrm{mg})$, benzaldehyde (0.5 mmol, $53 \mathrm{mg})$, and ammonium acetate $(1.0 \mathrm{mmol}, 77 \mathrm{mg})$ were added into

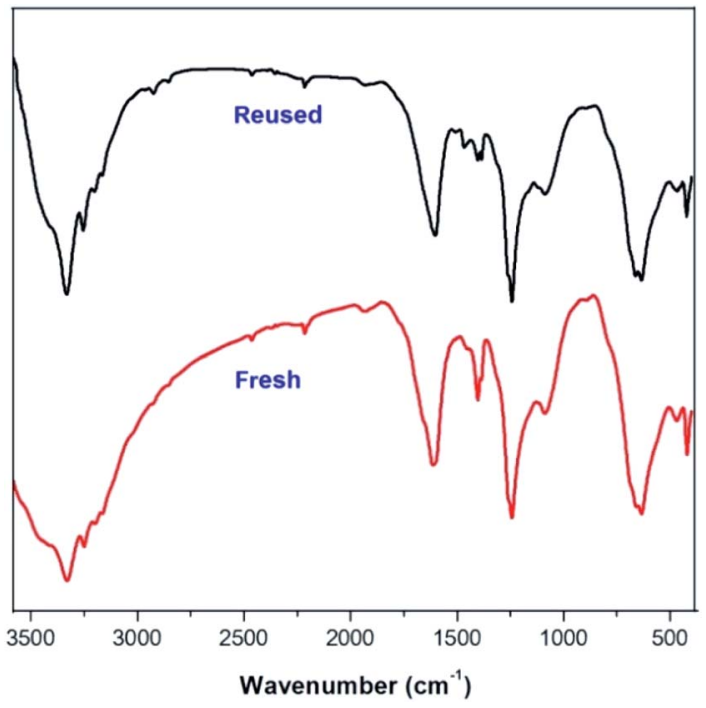

Fig. 5 FT-IR spectra of the fresh catalyst and the reused catalyst. 
a vessel with LADES@MNP (7.5\% mmol, $11 \mathrm{mg})$ for the synthesis of 2,4,5-triphenyl- $1 H$-imidazole. Benzil ( $0.5 \mathrm{mmol}, 105$ $\mathrm{mg}$ ), benzaldehyde $(0.5 \mathrm{mmol}, 53 \mathrm{mg})$, aniline $(0.5 \mathrm{mmol}, 47$ $\mathrm{mg})$ and ammonium acetate $(1.0 \mathrm{mmol}, 77 \mathrm{mg})$ were added into a vessel with LADES@MNP (7.5\% mmol, $11 \mathrm{mg})$ for the synthesis of 1,2,4,5-tetraphenyl imidazole. The mixture reaction was sonicated at room temperature for $2 \mathrm{~h}$. The reaction was monitored by TLC. The mixture dissolved in $5.0 \mathrm{~mL}$ ethyl acetate after completion of the reaction. The LADES@MNP catalyst was separated by a magnet and washed with acetone (3 $\times 5.0 \mathrm{~mL})$ and ethanol $(3 \times 5.0 \mathrm{~mL})$ for the next experiments. The organic solution was evaporated under reduced pressure to remove the solvent. The crude product was purified by crystallization in ethanol in order to afford the pure product. Finally, the pure product was defined by melting point and characterized by FT-IR, ${ }^{1} \mathrm{H}-\mathrm{NMR},{ }^{13} \mathrm{C}-\mathrm{NMR}$.

\section{Conclusions}

In conclusion, we have developed a novel magnetic nanoparticle supported Lewis acidic deep eutectic solvent and used as a catalyst in the one-pot multicomponent reactions to afford 2,4,5-trisubstituted and 1,2,4,5-tetrasubstituted imidazoles in good to excellent yields for the first time. Prominent features of the current method include high yield, milder and cleaner reaction, and work-up simplicity, magnetic separability, and reusability of the catalyst making it an exciting alternative to the existing methodologies.

\section{Conflicts of interest}

There are no conflicts to declare.

\section{Acknowledgements}

This research is funded by Vietnam National Foundation for Science and Technology Development (NAFOSTED) under grant number 104.01-2019.26.

\section{References}

1 E. L. Smith, A. P. Abbott and K. S. Ryder, Chem. Rev., 2014, 114, 11060-11082.

2 C. J. Clarke, W. C. Tu, O. Levers, A. Brohl and J. P. Hallett, Chem. Rev., 2018, 118, 747-800.

3 B. Liu, W. Fu, X. Lu, Q. Zhou and S. Zhang, ACS Sustainable Chem. Eng., 2018, 7, 3292-3300.

4 L. I. N. Tomé, V. Baião, W. da Silva and C. M. A. Brett, Appl. Mater. Today, 2018, 10, 30-50.

5 S. Hong, H. Lian, X. Sun, D. Pan, A. Carranza, J. A. Pojman and J. D. Mota-Morales, RSC Adv., 2016, 6, 89599-89608.

6 H. T. Nguyen and P. H. Tran, RSC Adv., 2016, 6, 98365-98368.

7 P. H. Tran, H. T. Nguyen, P. E. Hansen and T. N. Le, RSC Adv., 2016, 6, 37031-37038.
8 H. T. Nguyen, D. K. N. Chau and P. H. Tran, New J. Chem., 2017, 41, 12481-12489.

9 A. Wang, P. Xing, X. Zheng, H. Cao, G. Yang and X. Zheng, RSC Adv., 2015, 5, 59022-59026.

10 H. Maka, T. Spychaj and J. Adamus, RSC Adv., 2015, 5, 82813-82821.

11 P. H. Tran and A. H. T. Hang, RSC Adv., 2018, 8, 1112711133.

12 N. Azizi, M. Edrisi and F. Abbasi, Appl. Organomet. Chem., 2018, 32, e3901.

13 V. Polshettiwar, R. Luque, A. Fihri, H. Zhu, M. Bouhrara and J. M. Basset, Chem. Rev., 2011, 111, 3036-3075.

14 J. Miao, H. Wan and G. Guan, Catal. Commun., 2011, 12, 353356.

15 Q. Zhang, H. Su, J. Luo and Y. Wei, Green Chem., 2012, 14, 201-208.

16 J. Safari and Z. Zarnegar, C. R. Chim., 2013, 16, 920-928.

17 X. Liang, Ind. Eng. Chem. Res., 2014, 53, 17325-17332.

18 H. Tavakol and F. Keshavarzipour, Appl. Organomet. Chem., 2017, 31, e3811.

19 Y. Huang, Y. Wang, Q. Pan, Y. Wang, X. Ding, K. Xu, N. Li and Q. Wen, Anal. Chim. Acta, 2015, 877, 90-99.

20 N. Lamei, M. Ezoddin, M. S. Ardestani and K. Abdi, Anal. Bioanal. Chem., 2017, 409, 6113-6121.

21 P. T. Parvatkar, P. S. Parameswaran and S. G. Tilve, Chem. Eur. J., 2012, 18, 5460-5489.

22 M. M. Cecchini, C. Charnay, F. De Angelis, F. Lamaty, J. Martinez and E. Colacino, ChemSusChem, 2014, 7, 45-65.

23 M. Waheed, N. Ahmed, M. A Alsharif, M. I. Alahmdi and S. Mukhtar, ChemistrySelect, 2017, 2, 7946-7950.

24 D. Khan, N. Ahmed, M. A. Alsharif, M. I. Alahmdi and S. Mukhtar, ChemistrySelect, 2019, 4, 7585-7590.

25 A. Mohammadi, H. Keshvari, R. Sandaroos, B. Maleki, H. Rouhi, H. Moradi, Z. Sepehr and S. Damavandi, Appl. Catal., A, 2012, 429-430, 73-78.

26 M. B. Gawande, V. D. Bonifacio, R. Luque, P. S. Branco and R. S. Varma, ChemSusChem, 2014, 7, 24-44.

27 J. J. Gabla, S. R. Mistry and K. C. Maheria, Catal. Sci. Technol., 2017, 7, 5154-5167.

28 A. Khodairy, A. M. Ali and M. T. El-Wassimy, J. Heterocycl. Chem., 2017, 54, 3342-3349.

29 V. Kannan and K. Sreekumar, J. Mol. Catal. A: Chem., 2013, 376, 34-39.

30 A. Maleki, Z. Alrezvani and S. Maleki, Catal. Commun., 2015, 69, 29-33.

31 A. Shaabani, H. Sepahvand, S. E. Hooshmand and M. Borjian Boroujeni, Appl. Organomet. Chem., 2016, 30, 414-421.

32 M. Nejatianfar, B. Akhlaghinia and R. Jahanshahi, Appl. Organomet. Chem., 2017, e4095.

33 A. R. Moosavi-Zare, M. A. Zolfigol, V. Khakyzadeh, C. Böttcher, M. H. Beyzavi, A. Zare, A. Hasaninejad and R. Luque, J. Mater. Chem. A, 2014, 2, 770-777. 